\title{
Time spent in oxygen saturation $95-99 \%$ is associated with reduced mortality in critically ill patients with mechanical ventilation
}

\author{
Dawei Zhou, Zhimin Li, Guangzhi Shi ${ }^{*}$ and Jianxin Zhou*
}

To the Editor:

The administration of supplemental oxygen is one of the ubiquitous interventions in the intensive care unit (ICU) and can be life-saving for mechanically ventilated patients [1]. However, excessive oxygen could be detrimental. Recently, several studies comparing the effect of conservative and liberal oxygen therapy for critically ill patients did not achieve consistent results $[2,3]$. Furthermore, in patients with acute respiratory distress syndrome (ARDS), conservative oxygen therapy even had a signal of increased mortality and mesenteric ischemia [4]. Of note, the target oxygen levels in these studies were not the same. It is of paramount importance to elucidate oxygen targets to guide future research. In the present study, with a big database, we aimed to evaluate the association of the proportion of time within arterial oxygen saturation $\left(\mathrm{SpO}_{2}\right)$ with hospital mortality in an ICU population with mechanical ventilation (MV).

This study used data stored in the eICU (eicu-crd.mit. edu) database [5]. Adult patients admitted to ICU for the first time with MV during the first $24 \mathrm{~h}$ were included. The main exposure was $\mathrm{SpO}_{2}$, which was generally interfaced from bedside vital sign monitors as the 5-min median value. Thirteen categories of $\mathrm{SpO}_{2}$ were generated, which were $\leq 88 \%, 89 \%, 90 \%, 91 \%, 92 \%$, $93 \%, 94 \%, 95 \%, 96 \%, 97 \%, 98 \%, 99 \%$, and $100 \%$. The proportion of time spent (PTS) in different $\mathrm{SpO}_{2}$ categories for each patient was defined as the percentage

\footnotetext{
* Correspondence: 15866601260@163.com; bjttyyicu@126.com Department of Critical Care Medicine, Beijing Tiantan Hospital, Capital Medical University, Beijing, China
}

of the summarized time in each different $\mathrm{SpO}_{2}$ category divided by total time. Thus, during the first $24 \mathrm{~h}$, patients had $\mathrm{SpO}_{2}$ values that fell in the 13 categories and for each patient PTS in each of the predefined categories ranged from 0 to $100 \%$. PTS was examined as both a continuous and categorical variable. The primary outcome was hospital mortality. Multivariable logistic regression models including PTS within each of these $\mathrm{SpO}_{2}$ categories along with the confounders were used to analyze the association of PTS- $\mathrm{SpO}_{2}$ with mortality outcome.

A total of 25,669 patients from 186 hospitals were included (Table 1), including 21,326 (83\%) survivors and 4343 (17\%) non-survivors. The median fraction of inspired oxygen was $45 \%$ (IQR, 43 60\%) and the median duration of $\mathrm{MV}$ was 3 days (IQR, 2 5 days). After adjusted for confounders, PTS-SpO $\mathrm{P}_{2}$ of $\leq 88 \%$, $89 \%, 90 \%, 91 \%, 92 \%, 93 \%$, and $100 \%$ were associated with a higher odds ratio for hospital mortality; PTS$\mathrm{SpO}_{2}$ of $95 \%, 96 \%, 97 \%, 98 \%$, and $99 \%$ were associated with a lower odds ratio; and PTS-SpO $\mathrm{P}_{2}$ of $94 \%$ was not associated with hospital mortality (Fig. 1a). Based on the results, $\mathrm{SpO}_{2}$ was divided into three categories ( $\leq 94 \%, 95-99 \%$, and $100 \%)$. PTS-SpO within categories of $\leq 94 \%(p<0.001)$ and $100 \%(p<$ 0.001 ) were associated with a higher risk of hospital mortality, whereas an inverse trend was observed between PTS-SpO $\mathrm{S}_{2}$ of $95-99 \%(p<0.001)$ and hospital mortality (Fig. 1b).

The result of the present study was partially consistent with the British Thoracic Society guideline, which recommended the target of $\mathrm{SpO}_{2}$ 94-98\% [6]. In addition, the result could partly account for the discrepancy of the 
Table 1 Characteristics of study patients between survivors and non-survivors

\begin{tabular}{|c|c|c|c|c|}
\hline Variables & Total $(n=25,669)$ & Survivors $(n=21,326)$ & Non-survivors $(n=4343)$ & $p$ value \\
\hline Age, years (median, [IQR]) & $65(54,75)$ & $65(53,74)$ & $70(58,79)$ & $<0.001$ \\
\hline Gender, male $(n(\%))$ & $13,933(54)$ & $11,561(54)$ & $2372(55)$ & 0.636 \\
\hline BMI (median, [IQR]) & $28.3(23.9,34.4)$ & $28.5(24.1,34.6)$ & $27.4(23.2,33.1)$ & $<0.001$ \\
\hline \multicolumn{5}{|l|}{ Comorbidities (n (\%)) } \\
\hline Hypertension & $13,533(53)$ & $11,216(53)$ & $2317(53)$ & 0.371 \\
\hline Diabetes mellitus & $6149(24)$ & $5173(24)$ & $976(22)$ & 0.013 \\
\hline COPD & $5870(23)$ & $4919(23)$ & $951(22)$ & 0.099 \\
\hline Heart failure & $5011(20)$ & $4110(19)$ & $901(21)$ & 0.027 \\
\hline Cirrhosis & $443(2)$ & $335(2)$ & $108(2)$ & $<0.001$ \\
\hline Cancer & $411(2)$ & $269(1)$ & $142(3)$ & $<0.001$ \\
\hline Chronic renal failure & $3585(14)$ & $2871(13)$ & $714(16)$ & $<0.001$ \\
\hline ICU types $(n(\%))$ & & & & $<0.001$ \\
\hline Med-Surg ICU & $13,737(54)$ & $11,477(54)$ & $2260(52)$ & \\
\hline Cardiac ICU & $1636(6)$ & $1216(6)$ & $420(10)$ & \\
\hline CCU-CTICU & $2162(8)$ & $1843(9)$ & $319(7)$ & \\
\hline CSICU & $889(3)$ & $768(4)$ & $121(3)$ & \\
\hline CTICU & $1179(5)$ & $1083(5)$ & $96(2)$ & \\
\hline MICU & $2587(10)$ & $2088(10)$ & $499(11)$ & \\
\hline Neuro ICU & $1643(6)$ & $1295(6)$ & $348(8)$ & \\
\hline SICU & $1836(7)$ & $1556(7)$ & $280(6)$ & \\
\hline Admission diagnosis ( $n(\%))$ & & & & $<0.001$ \\
\hline Respiratory & $5910(23)$ & $5106(24)$ & $804(19)$ & \\
\hline Sepsis & $3660(14)$ & $2856(13)$ & $804(19)$ & \\
\hline Cardiac surgery & $3035(12)$ & $2847(14)$ & $88(2)$ & \\
\hline Non-cardiac surgery & $2495(10)$ & $2207(10)$ & $288(7)$ & \\
\hline Neurological & $2560(10)$ & $1985(9)$ & $575(13)$ & \\
\hline Cardiovascular & $2079(8)$ & $1783(8)$ & $296(7)$ & \\
\hline Cardiac arrest & $2143(8)$ & $1149(5)$ & $994(23)$ & \\
\hline Trauma & $1179(5)$ & $986(5)$ & $193(4)$ & \\
\hline Gastrointestinal & $461(2)$ & $378(2)$ & $83(2)$ & \\
\hline Others & $2147(8)$ & $1929(9)$ & $218(5)$ & \\
\hline TWM-PaO $2, \mathrm{mmHg}(n(\%))$ & & & & $<0.001$ \\
\hline$<60$ & $622(2)$ & $480(2)$ & $142(3)$ & \\
\hline $60-120$ & $10,593(41)$ & $8832(41)$ & $1761(41)$ & \\
\hline $120-300$ & $8226(32)$ & $6691(31)$ & $1535(35)$ & \\
\hline$>300$ & $579(2)$ & $453(2)$ & $126(3)$ & \\
\hline Missing $(n(\%))$ & $5649(22)$ & $4870(23)$ & 779 (18) & \\
\hline TWM-PaCO $2, \mathrm{mmHg}(n(\%))$ & & & & $<0.001$ \\
\hline$<35$ & $4420(17)$ & $3336(16)$ & $1084(25)$ & \\
\hline $35-45$ & $9555(37)$ & $8041(38)$ & $1514(35)$ & \\
\hline$>45$ & $5849(23)$ & $4928(23)$ & $921(21)$ & \\
\hline Missing (n (\%)) & $5845(23)$ & $5021(24)$ & $824(19)$ & \\
\hline TWM-pH (n (\%)) & & & & $<0.001$ \\
\hline$<7.35$ & $6868(27)$ & $5311(25)$ & $1557(36)$ & \\
\hline
\end{tabular}


Table 1 Characteristics of study patients between survivors and non-survivors (Continued)

\begin{tabular}{|c|c|c|c|c|}
\hline Variables & Total $(n=25,669)$ & Survivors $(n=21,326)$ & Non-survivors $(n=4343)$ & $p$ value \\
\hline $7.35-7.45$ & $10,085(39)$ & $8635(40)$ & $1450(33)$ & \\
\hline$>7.45$ & $2626(10)$ & $2136(10)$ & $490(11)$ & \\
\hline Missing $(n(\%))$ & $6090(24)$ & $5244(25)$ & $846(19)$ & \\
\hline 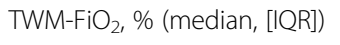 & $45(43,60)$ & $45(42,59)$ & $50(45,75)$ & $<0.001$ \\
\hline APACHE IV (median, [IQR]) & $68(50,89)$ & $63(48,83)$ & $92(72,115)$ & $<0.001$ \\
\hline SOFA (median, [IQR]) & $6(4,8)$ & $6(4,8)$ & $8(6,11)$ & $<0.001$ \\
\hline Vasopressors (n (\%)) & $5734(22)$ & 4135 (19) & $1599(37)$ & $<0.001$ \\
\hline Dialysis ( $n(\%))$ & $976(4)$ & $802(4)$ & $174(4)$ & 0.466 \\
\hline Ventilation days $(n(\%))$ & $3(2,5)$ & $3(2,4)$ & $4(2,7)$ & $<0.001$ \\
\hline
\end{tabular}

$I Q R$ interquartile range, $B M I$ body mass index, $C O P D$ chronic obstructive pulmonary disease, ICU intensive care unit, $C C U$ coronary care unit, $C T I C U$ cardiothoracic ICU, CSICU cardiac surgery ICU, MICU medical ICU, SICU surgical ICU, TWM time-weighted mean, $\mathrm{SpO}_{2}$ peripheral oxygen saturation, $\mathrm{PaO}_{2}$ partial pressure of arterial oxygen, $\mathrm{PaCO}_{2}$ partial pressure of arterial carbon dioxide, $\mathrm{FiO}_{2}$ fraction of inspired oxygen, APACHE Acute Physiology and Chronic Health Evaluation, SOFA sequential organ failure assessment

recent clinical trials of oxygen therapy, which adopted different target oxygen levels [2-4]. Despite several limitations to our study (e.g., retrospective design, potential residual confounders, unvalidated data from monitors, relatively short study period, lack of mode of MV, and missing data), our study provided observational evidence for a $\mathrm{SpO}_{2}$ target range of $95-99 \%$ with real-world data.
Further studies are warranted to validate the particular target.

In conclusion, the proportion of time spent in oxygen saturation $95-99 \%$ is associated with reduced mortality in critically ill patients with mechanical ventilation. These findings may have implications for the design of future trials of oxygen therapy.
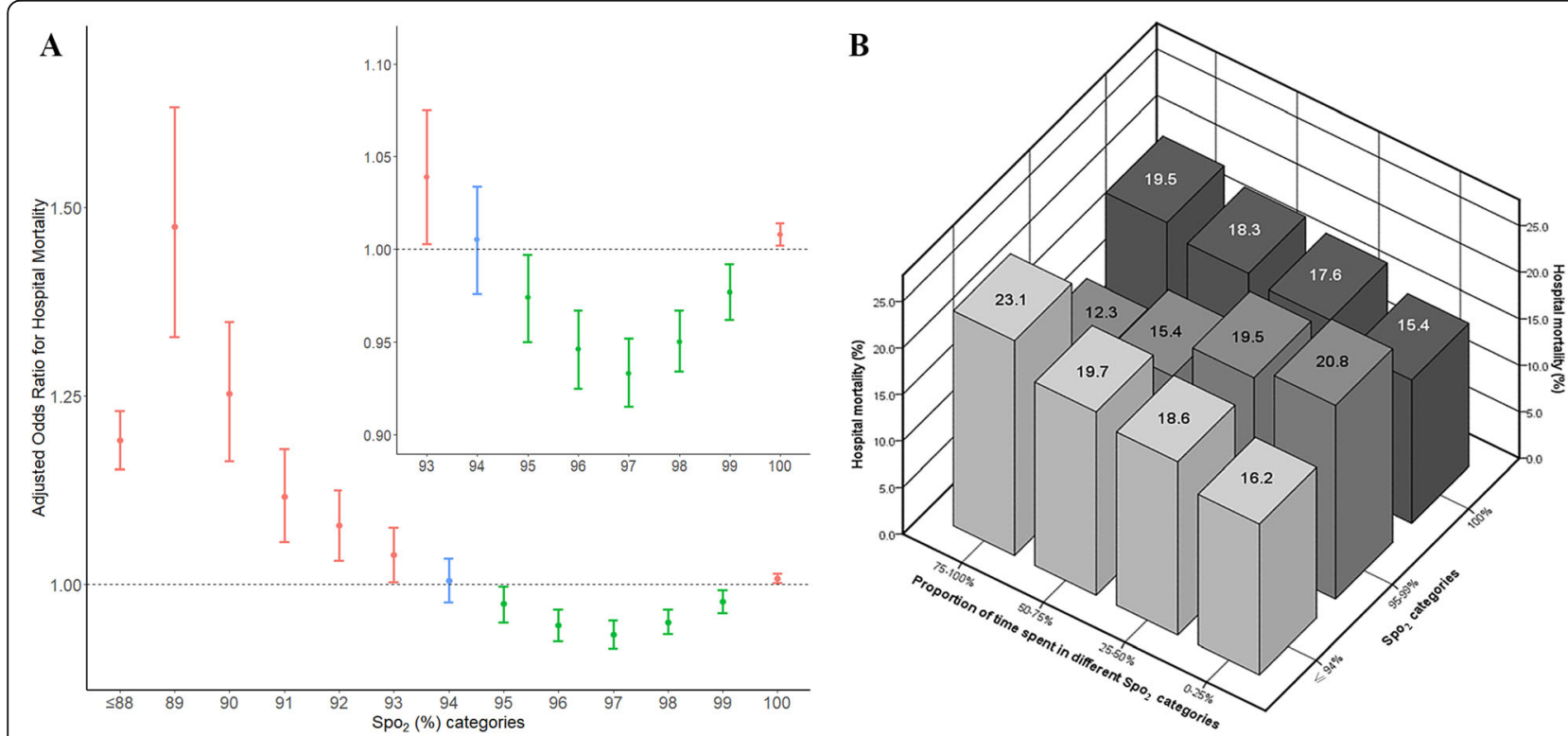

Fig. 1 a Adjusted odds ratio for hospital mortality according to different $\mathrm{SpO}_{2}$ categories. The proportion of time spent in thirteen different $\mathrm{SpO}_{2}$ categories ( $\leq 88 \%, 89 \%, 90 \%, 91 \%, 92 \%, 93 \%, 94 \%, 95 \%, 96 \%, 97 \%, 98 \%, 99 \%$, and 100\%) was considered as a continuous variable, ranging from 0 to $100 \%$, and was included in separate multivariable regression models along with the confounders. In total, 13 models were created. The adjusted odds ratio for each $\mathrm{SpO}_{2}$ category and $95 \%$ confidence intervals (error bars) were calculated after adjusting for age, body mass index (obesity or non-obesity), admission diagnosis, comorbidities (diabetes mellitus, cancer), time-weighted mean $\mathrm{FiO}_{2}$, time-weighted mean pH, timeweighted mean $\mathrm{PaCO}_{2}$, sequential organ failure assessment score (not including the respiratory part), and use of dialysis. An odds ratio is calculated per $5 \%$ increase in time in each given category. $\mathrm{SpO}_{2}$, arterial oxygen saturation; $\mathrm{FiO}_{2}$, fraction of inspired oxygen; $\mathrm{PaCO}$, partial pressure of arterial carbon dioxide. b Observed hospital mortality of four predefined time ranges $(0-25 \%, 25-50 \%, 50-75 \%$, and $75-100 \%)$ spent in three different $\mathrm{SpO}_{2}$ categories ( $\leq 94 \%, 95-99 \%$, and $\left.100 \%\right)$. Figures on each histogram column represented the crude hospital mortality 


\section{Abbreviations}

APACHE: Acute Physiology and Chronic Health Evaluation; ARDS: Acute respiratory distress syndrome; $\mathrm{FiO}_{2}$ : Fraction of inspired oxygen; ICU: Intensive care unit; IQR: Interquartile range; MV: Mechanical ventilation; OR: Odds ratio; $\mathrm{PaO}_{2}:$ Partial pressure of oxygen; $\mathrm{PaCO}_{2}:$ Partial pressure of arterial carbon dioxide; $\mathrm{PTS}-\mathrm{SpO}_{2}$ : Proportion of time spent in $\mathrm{SpO}_{2}$; SOFA: Sequential organ failure assessment; $\mathrm{SpO}_{2}$ : Arterial oxygen saturation; TWM: Time-weighted mean

\section{Acknowledgements}

None.

\section{Authors' contributions}

DW Z and JX Z conceived this study. DW Z extracted the data. DW Z, ZM L, and GZ S designed and performed the statistical analyses. DW Z wrote the first draft of the manuscript. GZ S and JX Z reviewed and modified the final manuscript. All authors read, critically reviewed, and approved the final manuscript.

\section{Funding}

This study was supported by the "Beijing Municipal Science and Technology Commission-Capital clinical application research" (Z181100001718068). The sponsor had no role in the study design, data collection, data analysis, data interpretation, or writing of the manuscript.

\section{Availability of data and materials}

Data analyzed during the present study are currently stored in the elCU database (eicu-crd.mit.edu). After completing the required training course (the Collaborative Institutional Training Initiative) and requesting access to the eICU Collaborative Research Database, researchers can seek to use the database.

\section{Ethics approval and consent to participate}

The schema of elCU was established in collaboration with Privacert (Cambridge, $M A)$, who certified the re-identification risk as meeting safe harbor standards (HIPAA Certification no. 1031219-2). All tables in elCU were deidentified to meet the safe harbor provision of the US HIPAA. Due to the HIPAA compliant deidentification in this database, our IRB requirement was waived.

\section{Consent for publication}

Not applicable.

\section{Competing interests}

None of the authors has declared a conflict of interest.

Received: 20 April 2020 Accepted: 1 July 2020

Published online: 09 July 2020

\section{References}

1. Siemieniuk RAC, Chu DK, Kim LH, Güell-Rous MR, Alhazzani W, Soccal PM, Karanicolas PJ, Farhoumand PD, Siemieniuk JLK, Satia I, et al. Oxygen therapy for acutely ill medical patients: a clinical practice guideline. BMJ (Clinical research ed). 2018;363:k4169.

2. Mackle D, Bellomo R, Bailey M, Beasley R, Deane A, Eastwood G, Finfer S, Freebairn R, King V, Linke N, et al. Conservative oxygen therapy during mechanical ventilation in the ICU. N Engl J Med. 2020;382(11):989-98.

3. Girardis M, Busani S, Damiani E, Donati A, Rinaldi L, Marudi A, Morelli A, Antonelli M, Singer M. Effect of conservative vs conventional oxygen therapy on mortality among patients in an intensive care unit: the oxygenICU randomized clinical trial. Jama. 2016;316(15):1583-9.

4. Barrot L, Asfar P, Mauny F, Winiszewski H, Montini F, Badie J, Quenot JP, PiliFloury S, Bouhemad B, Louis G, et al. Liberal or conservative oxygen therapy for acute respiratory distress syndrome. N Engl J Med. 2020;382(11):999-1008.

5. Pollard TJ, Johnson AEW, Raffa JD, Celi LA, Mark RG, Badawi O. The elCU Collaborative Research Database, a freely available multi-center database for critical care research. Scientific Data. 2018:5:180178.

6. O'Driscoll BR, Howard LS, Earis J, Mak V. BTS guideline for oxygen use in adults in healthcare and emergency settings. Thorax. 2017;72(Suppl 1):ii1-ii90.

\section{Publisher's Note}

Springer Nature remains neutral with regard to jurisdictional claims in published maps and institutional affiliations.

\section{Ready to submit your research? Choose BMC and benefit from:}

- fast, convenient online submission

- thorough peer review by experienced researchers in your field

- rapid publication on acceptance

- support for research data, including large and complex data types

- gold Open Access which fosters wider collaboration and increased citations

- maximum visibility for your research: over $100 \mathrm{M}$ website views per year

At BMC, research is always in progress.

Learn more biomedcentral.com/submissions 